\title{
Negative Impact of Coexisting Interstitial Lung Disease on Clinical Outcomes in Small-cell Lung Cancer Patients
}

\author{
KIMITAKA AKAIKE, KOICHI SARUWATARI, HIROKO OKABAYASHI, SHOHEI HAMADA, \\ YASUMIKO JODAI, TAKAYUKI JODAI, SHINYA SAKATA, SHINJI IYAMA, RYO SATO, \\ TOYOHISA IRIKI, YUSUKE TOMITA, SHO SAEKI, HIDENORI ICHIYASU and KAZUHIKO FUJII \\ Department of Respiratory Medicine, Kumamoto University Hospital, \\ Faculty of Life Sciences, Kumamoto University, Kumamoto, Japan
}

\begin{abstract}
Background/Aim: The impact of interstitial lung disease (ILD) on the clinical outcome of patients with smallcell lung cancer (SCLC) is not fully understood. The aim of this study was to investigate the impact of ILD on treatment and survival outcomes of SCLC patients. Patients and Methods: A retrospective analysis was performed on the clinical outcomes of SCLC patients, treated with chemotherapy, with or without ILD ([ILD group $(n=16)$ and non-ILD group $(n=51)]$. Results: Median PFS and OS were significantly shorter in the ILD group than in the non-ILD group (median PFS, 184 vs. 290 days, $p=0.008$; median OS, 236 vs. 691 days, $p<0.001$ ). Multivariate analysis revealed that coexisting ILD was an independent predictive factor of PFS (hazard ratio $[H R]=2.06$; $95 \%$ confidence interval $[C I]=1.01-4.18 ; p=0.046)$ and $O S$ $(H R=3.29 ; \quad 95 \% C I=1.53-7.08 ; \quad p=0.002)$. Conclusion: Coexisting ILD might be a negative predictive factor of PFS and OS of SCLC patients treated with chemotherapy.
\end{abstract}

Small-cell lung cancer (SCLC) accounts for approximately $13 \%$ of primary lung cancer cases and is categorized as limited disease (LD)-SCLC and extensive disease (ED)-SCLC based on treatment options. Standard-care for LD-SCLC and EDSCLC is chemoradiotherapy and platinum combined chemotherapy, respectively. Despite a high sensitivity to initial chemotherapy and radiotherapy, most patients with SCLC develop tumor relapse and have dismal prognosis $(1,2)$.

Interstitial lung disease (ILD) is characterized by inflammation and fibrosis of alveoli, distal airways, and septal

Correspondence to: Koichi Saruwatari, Department of Respiratory Medicine, Kumamoto University Hospital, Faculty of Life Sciences, Kumamoto University, 1-1-1 Honjo, Chuo-ku, Kumamoto 8608556, Japan. Tel: +81 963735012, Fax: +81 963735328, e-mail: ksaruwat@kuh.kumamoto-u.ac.jp

Key Words: Small-cell lung cancer, interstitial lung disease, chemotherapy, acute exacerbation. interstitium of lungs, and typical computed tomography (CT) findings of ILD include an interstitial shadow reflecting thickened septa, reticulation, areas of decreased attenuation, ground-glass opacities, and honeycombing (3). ILD, particularly idiopathic pulmonary fibrosis (IPF), is a risk factor for lung cancer; previous studies reported that lung cancer incidence in patients with IPF ranged from 13-20.4\%, which is higher than that in the general population (4-6). Evaluation of the causes of death in IPF patients revealed that acute exacerbation (AE) and chronic respiratory failure account for $64 \%$ of the deaths, whereas lung cancer alone accounts for $11 \%$ of the deaths (7).

$\mathrm{AE}$ is a serious obstacle in the treatment of lung cancer patients with ILD. The incidence rates of AE induced by chemoradiotherapy, radiotherapy, and chemotherapy in patients with concomitant ILD and lung cancer were $42.9 \%$, $16.7 \%$, and $20-26.6 \%$, respectively $(8,9)$. Moreover, mortality due to AE of ILD (AE-ILD) due to chemotherapy was reported to range from $29-50 \%$ (9-12). Thus, treatment strategies for lung cancer patients with ILD should be distinct from those in non-ILD patients.

In lung cancer patients with ILD, the rates of non-smallcell lung cancer (NSCLC) and SCLC were reported to be $62.5-63.3 \%$ and $30.2-36.5 \%$, respectively $(10,12)$. Several retrospective studies of NSCLC patients showed that the presence of ILD was a poor prognostic factor and a negative predictive factor for response to chemotherapy (13-16). However, the clinical impact of ILD in patients with SCLC treated with chemotherapy remains unclear. Therefore, we conducted a retrospective study to investigate the clinical features of SCLC patients with ILD and assess the impact of coexisting ILD on clinical outcomes including therapeutic response and prognosis.

\section{Patients and Methods}

Patients. Between April 2006 and March 2016, 87 SCLC patients were diagnosed at Kumamoto University Hospital. Among these, 72 
Table I. Patient characteristics.

\begin{tabular}{|c|c|c|c|c|c|}
\hline & \multicolumn{2}{|c|}{ Non-ILD $(\mathrm{n}=51)$} & \multicolumn{2}{|c|}{$\operatorname{ILD}(n=16)$} & \multirow[b]{2}{*}{$p$-Value } \\
\hline & $\mathrm{n}$ & $\%$ & $\mathrm{n}$ & $\%$ & \\
\hline \multicolumn{6}{|l|}{ Age, years } \\
\hline Median (range) & $67(45-85)$ & & $71(56-83)$ & & 0.955 \\
\hline$<65$ & 17 & 33.3 & 4 & 25.0 & \\
\hline$\geq 65$ & 34 & 66.7 & 12 & 75.0 & \\
\hline \multicolumn{6}{|l|}{ Gender } \\
\hline Male & 43 & 84.3 & 14 & 87.5 & 0.755 \\
\hline Female & 8 & 15.7 & 2 & 12.5 & \\
\hline \multicolumn{6}{|l|}{ Smoking } \\
\hline Yes & 48 & 94.1 & 15 & 93.8 & 0.957 \\
\hline No & 3 & 5.9 & 1 & 6.3 & \\
\hline \multicolumn{6}{|l|}{ PS } \\
\hline $0-1$ & 46 & 90.2 & 13 & 81.3 & 0.336 \\
\hline$\geq 2$ & 5 & 9.8 & 3 & 18.8 & \\
\hline \multicolumn{6}{|l|}{$\mathrm{LDH}, \mathrm{U} / \mathrm{l}$} \\
\hline Median (range) & $233(153-567)$ & & $245(147-1070)$ & & 0.407 \\
\hline$<240$ & 29 & 56.9 & 8 & 50.0 & \\
\hline$\geq 240$ & 22 & 43.1 & 8 & 50.0 & \\
\hline \multicolumn{6}{|l|}{ Stage } \\
\hline LD & 32 & 62.7 & 7 & 43.8 & 0.179 \\
\hline ED & 19 & 37.3 & 9 & 56.3 & \\
\hline \multicolumn{6}{|l|}{ ILD } \\
\hline UIP pattern & - & - & 12 & 75.0 & - \\
\hline Non-UIP pattern & - & - & 4 & 25.0 & \\
\hline \multicolumn{6}{|l|}{ Treatment } \\
\hline Chemoradiotherapy & 29 & 56.9 & 1 & 6.3 & $<0.001$ \\
\hline Chemotherapy & 22 & 43.1 & 15 & 93.8 & \\
\hline \multicolumn{6}{|l|}{ Regimen } \\
\hline Platinum + VP-16 & 42 & 82.3 & 16 & 100 & 0.196 \\
\hline Platinum + CPT-11 & 8 & 15.7 & 0 & 0 & \\
\hline Other & 1 & 2.0 & 0 & 0 & \\
\hline
\end{tabular}

ILD: Interstitial lung disease; PS: Eastern Cooperative Oncology Group performance status; LDH: lactate dehydrogenase; LD: limited disease; ED: extensive disease; UIP: usual interstitial pneumonia; VP-16: etoposide; CTP-11: irinotecan.

patients received first-line chemotherapy except for 12 and 3 patients who received best supportive care (BSC) and radiotherapy alone, respectively. After the exclusion of 5 patients who were lost to follow-up within the first 3 months after diagnosis due to transfer to another hospital, the remaining 67 patients were included in this retrospective study. The patients were divided into the ILD $(n=16)$ and non-ILD $(n=51)$ groups according to the diagnosis at the time of inclusion. The following baseline and clinical characteristics were reviewed and compared between the groups: age, sex, smoking status, Eastern Cooperative Oncology Group performance status (PS), serum lactate dehydrogenase (LDH), stage (LD or ED), type of treatment (chemoradiotherapy or chemotherapy alone), and specific chemotherapeutic regimens. The institutional review board of Kumamoto University Hospital approved of this study (IRBnumber 1451).

Diagnosis of ILD and AE of ILD. ILD diagnosis and classification as usual interstitial pneumonia (UIP) or non-UIP were based on the international consensus statement of the American Thoracic Society (ATS)/European Respiratory Society (ERS)/Japanese Respiratory Society (JRS)/Latin American Thoracic Association (ALAT). UIP pattern was defined by the following four features: subpleural and basal predominance, reticular abnormality, honeycombing with or without traction bronchiectasis, and absence of features listed as inconsistent with UIP pattern. AE-ILD was also based on the ATS/ERS/JRS/ALAT consensus statement as follows: subjective worsening of dyspnea within the past month; evidence of worsening of partial pressure of oxygen in arterial blood; new radiographic alveolar infiltrates; and absence of an alternative explanation including infection, pulmonary embolism, pneumothorax, worsening of malignant tumor, and heart failure (17). All CT scans were evaluated by 2 independent pulmonologists (K.A. and K.S.).

Outcome parameters and statistical analysis. Best overall response was assessed by the Response Evaluation Criteria in Solid Tumors version 1.1 (18). Overall response rate (ORR) was defined as the percentage of patients with complete response and partial response. Progression-free survival (PFS) was defined as the time from start of first-line chemotherapy to disease progression or death from any cause or last follow-up. Overall survival (OS) was defined as the time from the start of first-line chemotherapy to death from any cause or last follow-up. 
Table II. Treatment and chemotherapeutic regimen for patients with LC-SCLC and ED-SCLC.

\begin{tabular}{|c|c|c|c|c|c|c|c|c|c|c|}
\hline & \multicolumn{4}{|c|}{ LD-SCLC patients } & \multirow[t]{3}{*}{$p$-Value } & \multicolumn{4}{|c|}{ ED-SCLC patients } & \multirow[t]{3}{*}{$p$-Value } \\
\hline & \multicolumn{2}{|c|}{ Non-ILD ( $\mathrm{n}=32)$} & \multicolumn{2}{|c|}{ ILD $(n=7)$} & & \multicolumn{2}{|c|}{ Non-ILD (n=19) } & \multicolumn{2}{|c|}{ ILD (n=9) } & \\
\hline & $\mathrm{n}$ & $\%$ & $\mathrm{n}$ & $\%$ & & $\mathrm{n}$ & $\%$ & $\mathrm{n}$ & $\%$ & \\
\hline \multicolumn{11}{|l|}{ Treatment } \\
\hline Chemoradiotherapy & 27 & 84.4 & 1 & 14.3 & & 2 & 10.5 & 0 & 0 & \\
\hline Chemotherapy & 5 & 15.6 & 6 & 85.7 & $<0.001$ & 17 & 89.5 & 9 & 100.0 & 0.312 \\
\hline \multicolumn{11}{|l|}{ Regimen } \\
\hline Platinum + VP-16 & 31 & 96.9 & 7 & 100.0 & & 11 & 57.9 & 9 & 100.0 & \\
\hline Platinum + CPT-11 & 0 & 0 & 0 & 0 & & 8 & 42.1 & 0 & 0 & \\
\hline Others & 1 & 3.1 & 0 & 0 & 0.636 & 0 & 0 & 0 & 0 & 0.021 \\
\hline
\end{tabular}

LD: Limited disease; ED: extensive disease; ILD: interstitial lung disease; chemo: chemotherapy; RT: radiotherapy; VP-16: etoposide; CTP-11: irinotecan.

Fisher exact test and the chi-squared test were used for comparison of categorical variables between the 2 groups. PFS and OS were calculated by the Kaplan-Meier method and compared by the log-rank test. To evaluate the clinical impact of ILD on PFS and OS, multivariate analysis was performed using the Cox regression model. Clinical variables that were previously known to exert clinical and prognostic influence on SCLC were included in the multivariable analysis $(1,19,20)$. All $p$-values $<0.05$ were considered to indicate statistical significance. All statistical analyses were performed by Statistical Package for the Social Science (version 23.0; IBM, Armonk, NY, USA).

\section{Results}

Patient characteristics. Demographic and clinical patient characteristics are shown in Table I. There were no significant differences in age, sex, smoking status, PS, serum $\mathrm{LDH}$, and stage between the 2 groups, although the proportion of those receiving chemoradiotherapy was significantly lower in the ILD than in the non-ILD group (6.3\% vs. $56.9 \% ; p<0.001)$. Additionally, the proportion of LD-SCLC patients receiving chemoradiotherapy was lower in the ILD than in the non-ILD group (14.3\% vs. $84.4 \%$; $p<0.001$, Table II). All patients with ILD had platinum and etoposide (VP-16), and ED-SCLC patients in the non-ILD group had a significantly higher rate of treatment with irinotecan (CPT-11) than those in the ILD group $(42.1 \% \mathrm{vs}$. $0 \% ; p=0.021$, Table II). In the ILD group, 2 patients had connective tissue disease-associated ILD, including 1 patient with rheumatoid arthritis, polymyositis, and sclerosis and 1 patient with mixed connective tissue disease and rheumatoid arthritis, whereas the remaining 14 patients were diagnosed with idiopathic interstitial pneumonia (IPF, $n=11$; non-IPF, $\mathrm{n}=3$ ). Evaluation of CT scans revealed that UIP and non-UIP patterns were present in 12 and 4 patients, respectively. Among those with the non-UIP CT pattern, 1 and 3 patients had cellular non-specific and fibrotic interstitial pneumonia patterns, respectively.
Response to first-line chemotherapy. ORR of first-line chemotherapy is shown in Table III. ORR was significantly lower in the ILD than in the non-ILD group $(50.0 \% \mathrm{vs}$. $84.3 \% ; p=0.005)$. ORR for both LD- and ED-SCLC patients tended to be lower in the ILD than in the non-ILD group (LD-SCLC, $71.4 \%$ vs. 93.8\%, $p=0.078$; ED-SCLC, $33.3 \%$ vs. $68.4 \%, p=0.080)$.

Survival analysis. Median follow-up was 391 days (range=432,485 days). Median PFS was significantly shorter in the ILD than in the non-ILD group (184vs. 290 days, $p=0.008$, Figure 1A). Median PFS for both the LD-SCLC and ED-SCLC patients tended to be lower in the ILD than in the non-ILD group (LD-SCLC, 236 vs. 303 days, $p=0.174$, Figure 1B; EDSCLC, $143 v s .217$ days; $p=0.023$, Figure 1C). Median OS was also shorter in the ILD than in the non-ILD group (236 vs. 691 days; $p<0.001$, Figure 1D). Median OS for both the LD- and ED-SCLC patients was shorter in the ILD than in the non-ILD group (LD-SCLC, 347 vs. 935 days, $p=0.049$, Figure 1E; EDSCLC, 203 vs. 441 days; $p<0.001$, Figure 1F).

Subsequent chemotherapy. The proportion of second-line chemotherapy tended to be lower in the ILD than the non-ILD group (43.8\% vs. $64.7 \%, p=0.136$, Table IV). Among the second-line chemotherapy regimens, 17 (33.3\%) and 16 $(31.4 \%)$ of the 51 patients in the non-ILD group received platinum-based combination chemotherapy and amrubicin, respectively, whereas $3(18.8 \%)$ and $2(31.4 \%)$ of the 16 patients in the ILD group received topotecan and paclitaxel, respectively. The proportion of third-line chemotherapy was significantly lower in the ILD than in the non-ILD group (41.2\% vs. 6.3\%, $p=0.009)$. Among the third-line chemotherapy regimens, $12(23.5 \%)$ and $6(11.8 \%)$ patients received amrubicin and topotecan, respectively, in the non-ILD group, whereas only 1 patient in the ILD group received paclitaxel. 
Table III. Response to first-line chemotherapy.

\begin{tabular}{|c|c|c|c|c|c|c|c|c|c|}
\hline & \multicolumn{2}{|c|}{ All patients } & \multirow[t]{2}{*}{$p$-Value } & \multicolumn{2}{|c|}{ LD-SCLC patients } & \multirow[t]{2}{*}{$p$-Value } & \multicolumn{2}{|c|}{ ED-SCLC patients } & \multirow[t]{2}{*}{$p$-Value } \\
\hline & Non-ILD $(\mathrm{n}=51)$ & $\operatorname{ILD}(\mathrm{n}=16)$ & & Non-ILD $(n=32)$ & $\operatorname{ILD}(\mathrm{n}=7)$ & & Non-ILD $(n=19)$ & $\operatorname{ILD}(n=9)$ & \\
\hline CR & 11 & 3 & & 11 & 3 & & 0 & 0 & \\
\hline PR & 32 & 5 & & 19 & 2 & & 13 & 3 & \\
\hline SD & 3 & 5 & & 0 & 2 & & 3 & 3 & \\
\hline PD & 4 & 2 & & 1 & 0 & & 3 & 2 & \\
\hline NE & 1 & 1 & & 1 & 0 & & 0 & 1 & \\
\hline ORR & $84.3 \%$ & $50.0 \%$ & 0.005 & $93.8 \%$ & $71.4 \%$ & 0.078 & $68.4 \%$ & $33.3 \%$ & 0.080 \\
\hline
\end{tabular}

LD: Limited disease; ED: extensive disease; ILD: interstitial lung disease; CR: complete response; PR: partial response; SD: stable disease; PD: progressive disease; NE: not evaluable; ORR: overall response rate.

Table IV. Subsequent chemotherapy.

\begin{tabular}{|c|c|c|c|c|c|}
\hline & \multicolumn{2}{|c|}{ Non-ILD $(\mathrm{n}=51)$} & \multicolumn{2}{|c|}{$\operatorname{ILD}(\mathrm{n}=16)$} & \multirow[b]{2}{*}{$p$-Value } \\
\hline & $\mathrm{n}$ & $\%$ & $\mathrm{n}$ & $\%$ & \\
\hline Second-line chemotherapy & 33 & 64.7 & 7 & 43.8 & 0.136 \\
\hline Platinum doublet & 17 & 33.3 & 3 & 18.8 & \\
\hline AMR & 16 & 31.4 & 0 & 0 & \\
\hline TOP & 0 & 0 & 2 & 12.5 & \\
\hline CPT-11 & 0 & 0 & 0 & 0 & \\
\hline PTX & 0 & 0 & 2 & 12.5 & \\
\hline Third-line chemotherapy & 21 & 41.2 & 1 & 6.3 & 0.009 \\
\hline Platinum doublet & 1 & 0 & 0 & 0 & \\
\hline AMR & 12 & 23.5 & 0 & 0 & \\
\hline TOP & 6 & 11.8 & 0 & 0 & \\
\hline CPT-11 & 1 & 0 & 0 & 0 & \\
\hline PTX & 1 & 0 & 1 & 6.3 & \\
\hline
\end{tabular}

LD: Limited disease; ED: extensive disease; ILD: interstitial lung disease; chemo: chemotherapy; AMR: amrubicin; TOP: topotecan; CTP11: irinotecan; PTX: paclitaxel.

Predictive factors of PFS and OS. Multivariate analysis of PFS performed to evaluate the clinical impact of coexisting ILD (Table V) showed that ED-stage (hazard ratio [HR], 1.82; $95 \%$ confidence interval $[\mathrm{CI}]=1.03-3.23, p=0.040$ ) and coexisting ILD (HR, 2.06; 95\% CI $=1.01-4.18, p=0.046)$ were independent negative predictive factors. Multivariate analysis for OS showed that poor PS $(\geq 2) \quad(\mathrm{HR}=3.27$; 95\% CI $=1.18-9.03, p=0.023)$, ED-stage $(\mathrm{HR}=2.03 ; 95 \%$ $\mathrm{CI}=1.09-3.78, p=0.026)$, and coexisting ILD (HR=3.29; $95 \% \mathrm{CI}=1.53-7.08 ; p=0.002)$ were negative prognostic factors.

$A E$ of ILD. Among the 16 patients with coexisting ILD, 5 (31.3\%) experienced AE of ILD during the entire study period from the start of chemotherapy. Table VI summarizes the characteristics and clinical outcomes of
Table V. Multivariate analysis for PFS and OS.

\begin{tabular}{|c|c|c|c|c|}
\hline \multirow[t]{2}{*}{ Variable } & \multicolumn{2}{|c|}{ PFS } & \multicolumn{2}{|c|}{ OS } \\
\hline & HR $(95 \% \mathrm{CI})$ & $p$-Value & HR $(95 \% \mathrm{CI})$ & $p$-Value \\
\hline \multicolumn{5}{|l|}{ Age, years } \\
\hline $\begin{array}{l}\geq 65 \\
<65\end{array}$ & $\begin{array}{c}0.83(0.47-1.48) \\
\text { Ref }\end{array}$ & 0.526 & $\begin{array}{c}1.03(0.53-1.97) \\
\text { Ref }\end{array}$ & 0.937 \\
\hline \multicolumn{5}{|l|}{ Gender } \\
\hline Male & $0.80(0.35-1.85)$ & 0.605 & $0.75(0.29-1.93)$ & 0.549 \\
\hline Female & Ref & & Ref & \\
\hline \multicolumn{5}{|l|}{ PS } \\
\hline$\geq 2$ & $1.44(0.53-3.89)$ & 0.472 & $3.27(1.18-9.03)$ & 0.023 \\
\hline $0-1$ & Ref & & Ref & \\
\hline \multicolumn{5}{|l|}{ LDH, U/1 } \\
\hline$\geq 240$ & $1.49(0.84-2.64)$ & 0.169 & $1.26(0.65-2.42)$ & 0.493 \\
\hline$<240$ & Ref & & Ref & \\
\hline \multicolumn{5}{|l|}{ Stage } \\
\hline $\mathrm{ED}$ & $1.82(1.03-3.23)$ & 0.040 & $2.03(1.09-3.78)$ & 0.026 \\
\hline LD & Ref & & Ref & \\
\hline \multicolumn{5}{|l|}{ ILD } \\
\hline ILD & $2.06(1.01-4.18)$ & 0.046 & $3.29(1.53-7.08)$ & 0.002 \\
\hline Non-ILD & Ref & & Ref & \\
\hline
\end{tabular}

PFS: Progression-free survival; OS: overall survival; HR: hazard ratio; 95\%CI: 95\% confidence interval; PS: Eastern Cooperative Oncology Group performance status; LDH: lactate dehydrogenase; LD: limited disease; ED: extensive disease; ILD: interstitial lung disease; Ref: reference.

these patients. All 5 patients who developed AE of ILD had UIP pattern. Additionally, 4 patients had IPF. Regarding treatment, 3,1 , and 1 patient received platinum plus VP16, topotecan, and paclitaxel, respectively. All 5 patients received steroid therapy, including 1 patient who was administered steroid pulse therapy with methylprednisolone. Two patients with AE-ILD died within 2 weeks after the onset of $\mathrm{AE}$, only 1 patient received subsequent chemotherapy after $\mathrm{AE}$, and the remaining 2 patients received BSC. 
A

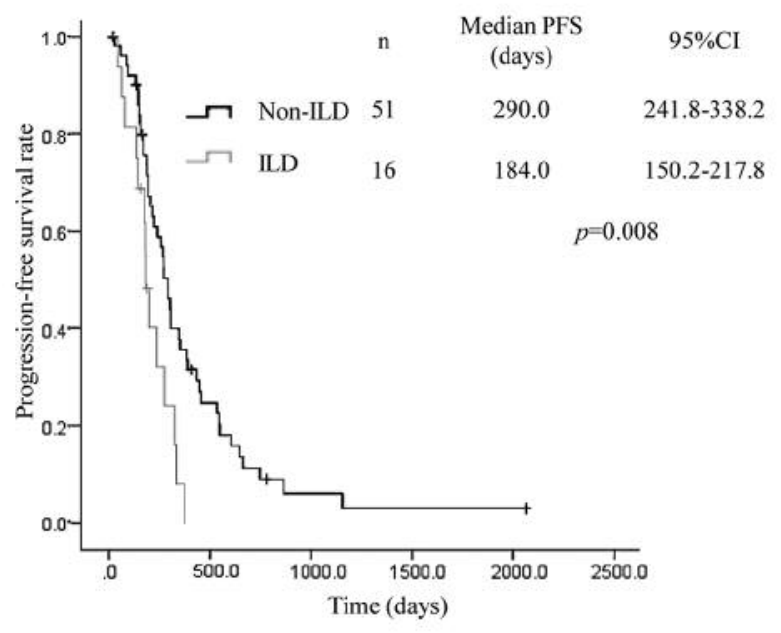

C

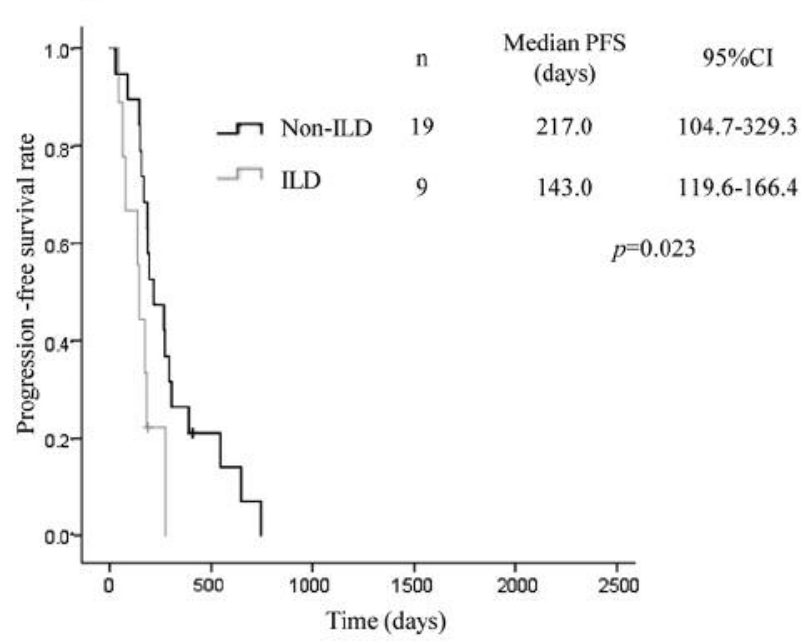

$\mathbf{E}$

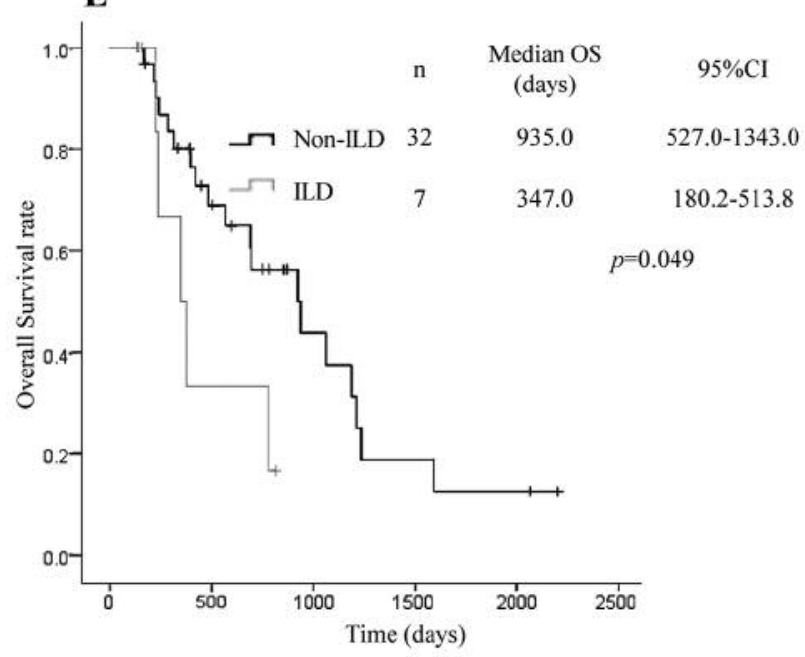

B

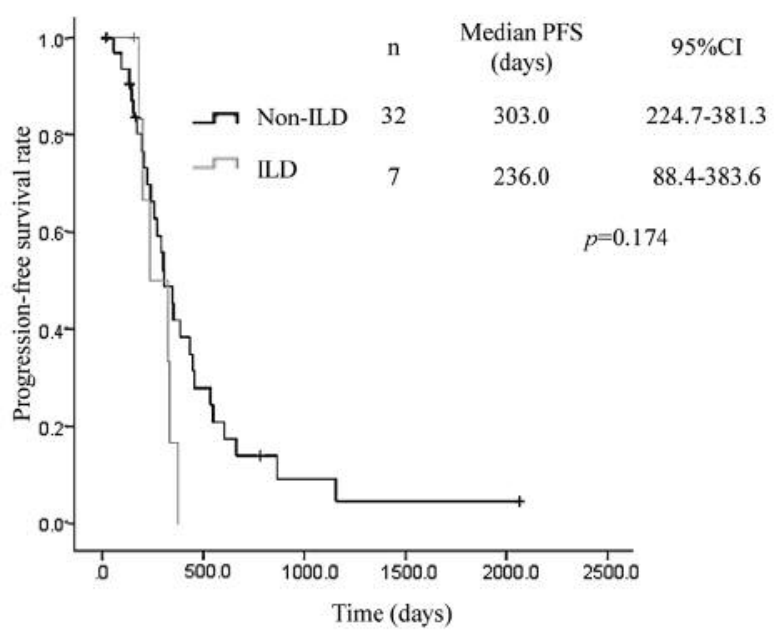

D
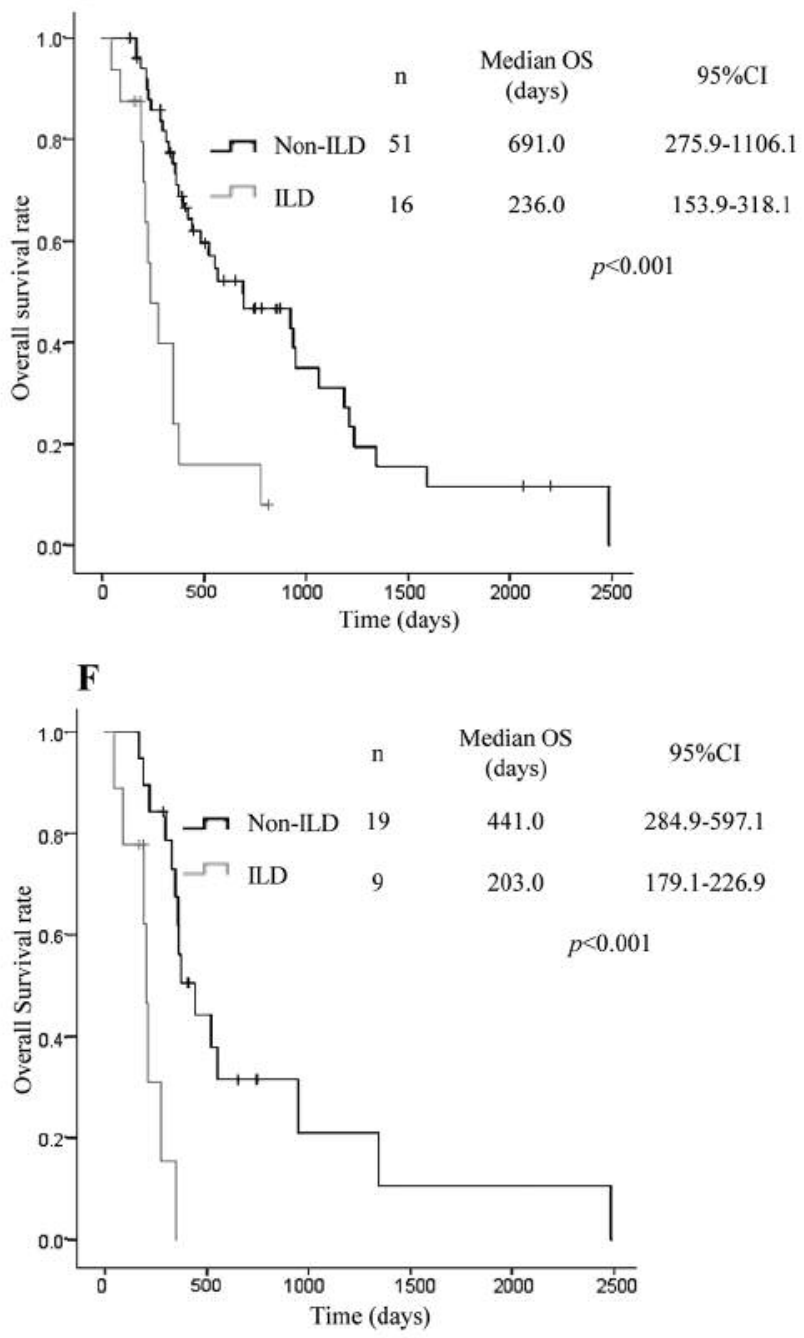

Figure 1. Kaplan-Meier survival curves for progression-free survival (PFS) and overall survival (OS) of patients with small-cell lung cancer (SCLC) with or without interstitial lung disease (ILD). PFS in all patients (A), those with limited disease (LD)-SCLC (B), and those with extensive disease (ED)-SCLC $(C)$. OS in all patients $(D)$, those with LD-SCLC $(E)$, and those with ED-SCLC $(F)$. 
Table VI. Acute exacerbation of patients with interstitial lung disease.

\begin{tabular}{ccccccccc}
\hline Case & Gender & Age, years & UIP/non-UIP & Regimen & Treatment line & Outcome of AE & OS after AE (days) & Subsequent therapy \\
\hline 1 & M & 56 & UIP & CDDP+VP-16 & 1st line & Recovery & 225 & PTX \\
2 & M & 59 & UIP & TOP & 2nd line & Death & 11 & $(-)$ \\
3 & M & 72 & UIP & PTX & 2nd line & Recovery & 76 & BSC \\
4 & F & 74 & UIP & CBDCA+VP-16 & 1st line & Death & 12 & $(-)$ \\
5 & M & 77 & UIP & CBDCA+VP-16 & 1st line & Recovery & $28^{*}$ & BSC \\
\hline
\end{tabular}

ILD: Interstitial lung disease; UIP: usual interstitial pneumonia pattern; AE: acute exacerbation; M: Male; F: Female; CDDP: cisplatin; CBDCA: carboplatin; VP-16: etoposide; TOP: topotecan; PTX: paclitaxel; BSC: best supportive care. ${ }^{*}$ Censored due to transfer to hospital.

\section{Discussion}

The present study demonstrated that $23.9 \%$ of SCLC patients treated with chemotherapy had concomitant ILD and that there were no significant differences in the characteristics between those with ILD and without ILD. The ORR, PFS, and OS rates were significantly worse in the ILD group than in the non-ILD group, and multivariate analyses revealed that coexisting ILD was a negative predictive factor for PFS and OS in SCLC patients treated with chemotherapy.

Several retrospective studies showed that 9.0\%-24.3\% of NSCLC patients were complicated with ILD at diagnosis (12, 16). In the current study, the proportion of ILD in SCLC patients $(23.9 \%)$ was similar to that reported in previous studies on NSCLC $(12,16)$. SCLC is strongly associated with smoking, which is also a recognized risk factor for several ILD types such as respiratory bronchiolitis-ILD, desquamative interstitial pneumonitis, IPF, and combined pulmonary fibrosis and emphysema $(1,21,22)$. Since ILD is a relatively common complication in SCLC patients, establishment of an optimal treatment strategy for patients with SCLC and coexisting ILD is critical.

The present study showed that ORR in patients with ILD was lower than that in those without ILD and that coexisting ILD was a negative predictive factor, suggesting that ILD might be associated with resistance to chemotherapy. Kanaji et al. similarly reported that NSCLC patients with ILD had lower response rates to chemotherapy/molecular target therapy when compared with those without ILD. (16) Multiple cytokines and growth factors including vascular endothelial growth factor (VEGF) and transforming growth factor $\beta$ (TGF- $\beta$ ) were shown to be associated with pulmonary fibrosis $(23,24)$. Previous studies showed that VEGF mRNA expression and TGF- $\beta$ concentration in bronchoalveolar lavage fluid of IPF patients were elevated compared to those without IPF (25-27). VEGF is a major regulator of angiogenesis that is essential for tumor progression and metastasis $(28,29)$. TGF- $\beta$ was shown to play an important role in epithelial-mesenchymal transition, which is associated with chemoresistance (30). Although we did not evaluate VEGF and TGF- $\beta$ in bronchoalveolar lavage fluid of
SCLC patients with ILD, these abundant tumor-promoting and chemoresistance factors in ILD patients might be associated with lower response and shorter PFS.

This analysis showed that coexisting ILD was a negative prognostic factor in SCLC patients treated with chemotherapy. Togashi et al. reported that median OS was significantly shorter in SCLC patients with coexisting ILD than those without coexisting ILD (10.7 vs. 17.8 months) and that coexisting ILD was a negative prognostic factor, consistent with the present study (19). Possible factors associated with worse prognosis in SCLC patients with ILD are lower frequency of chemoradiotherapy and subsequent chemotherapy. First, a meta-analysis evaluating thoracic radiotherapy for LD-SCLC found that chemoradiotherapy for LD-SCLC significantly prolonged survival compared with chemotherapy alone (31). In the present study, the proportion of chemoradiotherapy in the ILD group (only 1 in 7 LDSCLC patients) was significantly lower than that in the nonILD group. One possible reason for the lower chemoradiotherapy rate in the ILD group is physicians' avoidance of chemoradiotherapy for SCLC patients with ILD due to concerns regarding AE of ILD being precipitated by chemoradiotherapy. Second, the proportion of patients receiving subsequent chemotherapy beyond first-line chemotherapy tended to be lower in the ILD than in the nonILD group. A randomized phase III trial comparing topotecan with BSC showed that topotecan prolonged survival in the second-line setting (32). Additionally, several agents such as amrubicin and CPT-11 were reportedly effective as salvage therapy for recurrent SCLC patients (33-35). However, amrubicin and CPT-11 are contraindicated for ILD patients in Japan, due to the high risk of AE. Since the selection of chemotherapeutic regimens in Japanese SCLC patients with ILD is limited, further development of effective and safe treatments for patients with ILD is needed.

Several retrospective studies showed that the incidence of AE-ILD in lung cancer patients with ILD receiving chemotherapy was $20 \%-26.6 \%,(8,9)$ and that the mortality of AE-ILD was remarkably high between $29 \%$ and 50\% (9-12). In this study, 5 (31\%) of the 16 SCLC patients with ILD 
experienced $\mathrm{AE}$ and 2 (40\%) patients died of AE-ILD, consistent with previous reports (8-12). Moreover, all 5 patients with AE-ILD had the UIP pattern, including 4 patients diagnosed with IPF. Since AE-ILD is a life-threating adverse event, strategies for prevention of AE-ILD during chemotherapy should be developed for patients with ILD. For example, nintedanib is a tyrosine kinase inhibitor that targets multiple receptors including fibroblast growth factor, platelet-derived growth factor, and VEGF. A recent analysis of data pooled from the TOMORROW and INPLUSIS trials comparing nintedanib to placebo in IPF patients showed that the HR of time to first $\mathrm{AE}$ was $0.53(95 \% \mathrm{CI}=0.34-0.83 ; p=0.0047)$ in favor of nintedanib and that the proportion of patients with $\mathrm{AE}$ was lower in the nintedanib group than in the placebo group $(4.6 \%$ vs. $8.7 \%$ ) (36). To evaluate whether nintedanib prolongs time to AE of IPF, a currently ongoing randomized trial is comparing nintedanib combined with carboplatin plus nab-paclitaxel with carboplatin plus nab-paclitaxel alone for patients with NSCLC and IPF (37). Therefore, SCLC patients with ILD might benefit from chemotherapy plus nintedanib.

The present study has several limitations. First, this was a retrospective single-center study including only Japanese patients. AE of Japanese patients with IPF were reported to be more frequent than in other ethnic groups $(7,17)$. Second, potential clinical factors affecting prognosis such as pulmonary function and serum Krebs von den Lungen-6 (KL-6) levels were not evaluated. A decline in forced vital capacity of $>10 \%$ within 6 months and baseline serum KL- 6 level of $>1,000$ $\mathrm{U} / \mathrm{ml}$ were reported as sensitive predictors of OS $(38,39)$. Further large-sized studies including other ethnic groups and ILD prognostic factors are warranted to elucidate the clinical significance of coexisting ILD in SCLC.

In conclusion, the present study showed that coexisting ILD might be a negative predictive factor of ORR, PFS, and OS in SCLC patients treated with chemotherapy. Moreover, the incidence of AE-ILD was higher in SCLC patients with ILD. Thus, SCLC patients with ILD might require distinctive treatment strategies compared with those without ILD.

\section{Conflicts of Interest}

The Authors declare that they have no conflicts of interest.

\section{Acknowledgements}

The Authors are grateful to Ms. Tamura and Ms. Tashiro for their support.

\section{References}

1 van Meerbeeck JP, Fennell DA and De Ruysscher DK: Small-cell lung cancer. Lancet (London, England) 378: 1741-1755, 2011.

2 Fruh M, De Ruysscher D, Popat S, Crino L, Peters S and Felip E: Small-cell lung cancer (SCLC): ESMO Clinical Practice
Guidelines for diagnosis, treatment and follow-up. Ann Oncol 24: vi99-105, 2013.

3 Bourke SJ: Interstitial lung disease: progress and problems. Postgrad Med J 82: 494-499, 2006.

4 Ozawa Y, Suda T, Naito T, Enomoto N, Hashimoto D, Fujisawa $\mathrm{T}$, Nakamura $\mathrm{Y}$, Inui $\mathrm{N}$, Nakamura $\mathrm{H}$ and Chida $\mathrm{K}$ : Cumulative incidence of and predictive factors for lung cancer in IPF. Respirology (Carlton, Vic) 14: 723-728, 2009.

5 Kreuter M, Ehlers-Tenenbaum S, Schaaf M, Oltmanns U, Palmowski K, Hoffmann H, Schnabel PA, Heussel CP, Puderbach M, Herth FJ and Warth A: Treatment and outcome of lung cancer in idiopathic interstitial pneumonias. Sarcoidosis Vasc Diffuse Lung Dis 31: 266-274, 2015.

6 Tomassetti S, Gurioli C, Ryu JH, Decker PA, Ravaglia C, Tantalocco P, Buccioli M, Piciucchi S, Sverzellati N, Dubini A, Gavelli G, Chilosi M and Poletti V: The impact of lung cancer on survival of idiopathic pulmonary fibrosis. Chest 147: 157-164, 2015.

7 Natsuizaka M, Chiba H, Kuronuma K, Otsuka M, Kudo K, Mori M, Bando M, Sugiyama Y and Takahashi H: Epidemiologic survey of Japanese patients with idiopathic pulmonary fibrosis and investigation of ethnic differences. Am J Respir Crit Care Med 190: 773-779, 2014.

8 Minegishi Y, Takenaka K, Mizutani H, Sudoh J, Noro R, Okano T, Azuma A, Yoshimura A, Ando M, Tsuboi E, Kudoh S and Gemma A: Exacerbation of idiopathic interstitial pneumonias associated with lung cancer therapy. Intern Med 48: 665-672, 2009.

9 Shukuya T, Ishiwata T, Hara M, Muraki K, Shibayama R, Koyama R and Takahashi K: Carboplatin plus weekly paclitaxel treatment in non-small cell lung cancer patients with interstitial lung disease. Anticancer Res 30: 4357-4361, 2010.

10 Kenmotsu H, Naito T, Kimura M, Ono A, Shukuya T, Nakamura Y, Tsuya A, Kaira K, Murakami H, Takahashi T, Endo M and Yamamoto N: The risk of cytotoxic chemotherapy-related exacerbation of interstitial lung disease with lung cancer. $\mathbf{J}$ Thorac Oncol 6: 1242-1246, 2011.

11 Yoshida T, Yoh K, Goto K, Niho S, Umemura S, Ohmatsu H and Ohe Y: Safety and efficacy of platinum agents plus etoposide for patients with small cell lung cancer with interstitial lung disease. Anticancer Res 33: 1175-1179, 2013.

12 Kakiuchi S, Hanibuchi M, Tezuka T, Saijo A, Otsuka K, Sakaguchi S, Toyoda Y, Goto H, Kawano H, Azuma M, Ogushi F and Nishioka Y: Analysis of acute exacerbation of interstitial lung disease associated with chemotherapy in patients with lung cancer: A feasibility of S-1. Respir Invest 55: 145-152, 2017.

13 Kudoh S, Kato H, Nishiwaki Y, Fukuoka M, Nakata K, Ichinose Y, Tsuboi M, Yokota S, Nakagawa K, Suga M, Jiang H, Itoh Y, Armour A, Watkins C, Higenbottam T and Nyberg F: Interstitial lung disease in Japanese patients with lung cancer: a cohort and nested case-control study. Am J Respir Crit Care Med 177: 13481357,2008

14 Miyazaki K, Satoh H, Kurishima K, Nakamura R, Ishikawa H, Kagohashi K, Ohara G and Hizawa N: Impact of interstitial lung disease on survival for patients with non-small cell lung cancer. Anticancer Res 29: 2671-2674, 2009.

15 Minegishi Y, Sudoh J, Kuribayasi H, Mizutani H, Seike M, Azuma A, Yoshimura A, Kudoh S and Gemma A: The safety and efficacy of weekly paclitaxel in combination with carboplatin for advanced non-small cell lung cancer with idiopathic interstitial pneumonias. Lung Cancer 71: 70-74, 2011. 
16 Kanaji N, Tadokoro A, Kita N, Murota M, Ishii T, Takagi T, Watanabe N, Tojo Y, Harada S, Hasui Y, Kadowaki N and Bandoh $\mathrm{S}$ : Impact of idiopathic pulmonary fibrosis on advanced nonsmall cell lung cancer survival. J Cancer Res Clin Oncol 142: 1855-1865, 2016.

17 Raghu G, Collard HR, Egan JJ, Martinez FJ, Behr J, Brown KK, Colby TV, Cordier JF, Flaherty KR, Lasky JA, Lynch DA, Ryu JH, Swigris JJ, Wells AU, Ancochea J, Bouros D, Carvalho C, Costabel U, Ebina M, Hansell DM, Johkoh T, Kim DS, King TE Jr., Kondoh Y, Myers J, Muller NL, Nicholson AG, Richeldi L, Selman M, Dudden RF, Griss BS, Protzko SL and Schunemann HJ: An official ATS/ERS/JRS/ALAT statement: idiopathic pulmonary fibrosis: evidence-based guidelines for diagnosis and management. Am J Respir Crit Care Med 183: 788-824, 2011.

18 Eisenhauer EA, Therasse P, Bogaerts J, Schwartz LH, Sargent D, Ford R, Dancey J, Arbuck S, Gwyther S, Mooney M, Rubinstein L, Shankar L, Dodd L, Kaplan R, Lacombe D and Verweij J: New response evaluation criteria in solid tumours: revised RECIST guideline (version 1.1). Eur J Cancer 45: 228-247, 2009.

19 Togashi Y, Masago K, Handa T, Tanizawa K, Okuda C, Sakamori $\mathrm{Y}$, Nagai H, Kim YH and Mishima M: Prognostic significance of preexisting interstitial lung disease in Japanese patients with small-cell lung cancer. Clin Lung Cancer 13: 304-311, 2012.

20 Kashiwabara K, Semba H, Fujii S, Tsumura S and Aoki R: Difference in benefit of chemotherapy between small cell lung cancer patients with interstitial pneumonia and patients with non-small cell lung cancer. Anticancer Res 35: 1065-1071, 2015.

21 Devesa SS, Bray F, Vizcaino AP and Parkin DM: International lung cancer trends by histologic type: male:female differences diminishing and adenocarcinoma rates rising. Int J Cancer 117: 294-299, 2005.

22 Travis WD, Costabel U, Hansell DM, King TE, Jr., Lynch DA, Nicholson AG, Ryerson CJ, Ryu JH, Selman M, Wells AU, Behr J, Bouros D, Brown KK, Colby TV, Collard HR, Cordeiro CR, Cottin V, Crestani B, Drent M, Dudden RF, Egan J, Flaherty K, Hogaboam C, Inoue Y, Johkoh T, Kim DS, Kitaichi M, Loyd J, Martinez FJ, Myers J, Protzko S, Raghu G, Richeldi L, Sverzellati N, Swigris J and Valeyre D: An official American Thoracic Society/European Respiratory Society statement: Update of the international multidisciplinary classification of the idiopathic interstitial pneumonias. Am J Respir Crit Care Med 188: 733-748, 2013.

23 Hostettler KE, Zhong J, Papakonstantinou E, Karakiulakis G, Tamm M, Seidel P, Sun Q, Mandal J, Lardinois D, Lambers C and Roth M: Anti-fibrotic effects of nintedanib in lung fibroblasts derived from patients with idiopathic pulmonary fibrosis. Respir Res 15: 157, 2014.

24 Grimminger F, Gunther A and Vancheri C: The role of tyrosine kinases in the pathogenesis of idiopathic pulmonary fibrosis. Eur Respir J 45: 1426-1433, 2015.

25 Khalil N, Parekh TV, O'Connor R, Antman N, Kepron W, Yehaulaeshet T, Xu YD and Gold LI: Regulation of the effects of TGF-beta 1 by activation of latent TGF-beta 1 and differential expression of TGF-beta receptors ( $\mathrm{T}$ beta R-I and T beta R-II) in idiopathic pulmonary fibrosis. Thorax 56: 907-915, 2001.

26 Antoniou KM, Soufla G, Proklou A, Margaritopoulos G, Choulaki C, Lymbouridou R, Samara KD, Spandidos DA and Siafakas NM: Different activity of the biological axis VEGF-Flt1 (fms-like tyrosine kinase 1) and CXC chemokines between pulmonary sarcoidosis and idiopathic pulmonary fibrosis: a bronchoalveolar lavage study. Clin Dev Immunol 2009: 537929, 2009.
27 Inomata M, Nishioka Y and Azuma A: Nintedanib: evidence for its therapeutic potential in idiopathic pulmonary fibrosis. Core Evid 10: 89-98, 2015.

28 Carmeliet P: Angiogenesis in life, disease and medicine. Nature 438: 932-936, 2005.

29 Ferrara N and Kerbel RS: Angiogenesis as a therapeutic target. Nature 438: 967-974, 2005.

30 Legras A, Pecuchet N, Imbeaud S, Pallier K, Didelot A, Roussel H, Gibault L, Fabre E, Le Pimpec-Barthes F, Laurent-Puig P and Blons $\mathrm{H}$ : Epithelial-to-mesenchymal transition and microRNAs in lung cancer. Cancers (Basel) 9, 2017. doi: 10.3390/cancers9080101.

31 Pignon JP, Arriagada R, Ihde DC, Johnson DH, Perry MC, Souhami RL, Brodin O, Joss RA, Kies MS, Lebeau B et al: A meta-analysis of thoracic radiotherapy for small-cell lung cancer. N Engl J Med 327: 1618-1624, 1992.

32 O'Brien ME, Ciuleanu TE, Tsekov H, Shparyk Y, Cucevia B, Juhasz G, Thatcher N, Ross GA, Dane GC and Crofts T: Phase III trial comparing supportive care alone with supportive care with oral topotecan in patients with relapsed small-cell lung cancer. J Clin Oncol 24: 5441-5447, 2006.

33 Masuda N, Fukuoka M, Kusunoki Y, Matsui K, Takifuji N, Kudoh S, Negoro S, Nishioka M, Nakagawa K and Takada M: CPT-11: a new derivative of camptothecin for the treatment of refractory or relapsed small-cell lung cancer. J Clin Oncol 10: 1225-1229, 1992.

34 Inoue A, Sugawara S, Yamazaki K, Maemondo M, Suzuki T, Gomi $\mathrm{K}$, Takanashi $\mathrm{S}$, Inoue $\mathrm{C}$, Inage $\mathrm{M}$, Yokouchi $\mathrm{H}$, Watanabe $\mathrm{H}$, Tsukamoto T, Saijo Y, Ishimoto O, Hommura F, and Nukiwa T: Randomized phase II trial comparing amrubicin with topotecan in patients with previously treated small-cell lung cancer: North Japan Lung Cancer Study Group Trial 0402. J Clin Oncol 26: 5401-5406, 2008.

35 von Pawel J, Jotte R, Spigel DR, O'Brien ME, Socinski MA, Mezger J, Steins M, Bosquee L, Bubis J, Nackaerts K, Trigo JM, Clingan P, Schutte W, Lorigan P, Reck M, Domine M, Shepherd FA, Li S and Renschler MF: Randomized phase III trial of amrubicin versus topotecan as second-line treatment for patients with small-cell lung cancer. J Clin Oncol 32: 4012-4019, 2014.

36 Richeldi L, Cottin V, du Bois RM, Selman M, Kimura T, Bailes Z, Schlenker-Herceg R, Stowasser S and Brown KK: Nintedanib in patients with idiopathic pulmonary fibrosis: Combined evidence from the TOMORROW and INPULSIS $((\mathrm{R}))$ trials. Respir Med 113: 74-79, 2016.

37 Otsubo K, Kishimoto J, Kenmotsu H, Minegishi Y, Ichihara E, Shiraki A, Kato T, Atagi S, Horinouchi H, Ando M, Kondoh Y, Kusumoto M, Ichikado K, Yamamoto N, Nakanishi Y and Okamoto I: Treatment Rationale and Design for J-SONIC: A randomized study of carboplatin plus nab-paclitaxel with or without nintedanib for advanced non-small-cell lung cancer with idiopathic pulmonary fibrosis. Clin Lung Cancer 19: e5-e9, 2018.

38 Yokoyama A, Kondo K, Nakajima M, Matsushima T, Takahashi T, Nishimura M, Bando M, Sugiyama Y, Totani Y, Ishizaki T, Ichiyasu $\mathrm{H}$, Suga M, Hamada $\mathrm{H}$ and Kohno N: Prognostic value of circulating KL-6 in idiopathic pulmonary fibrosis. Respirology 11: 164-168, 2006.

39 Zappala CJ, Latsi PI, Nicholson AG, Colby TV, Cramer D, Renzoni EA, Hansell DM, du Bois RM and Wells AU: Marginal decline in forced vital capacity is associated with a poor outcome in idiopathic pulmonary fibrosis. Eur Respir J 35: 830-836, 2010.

Received October 5, 2018

Revised October 19, 2018

Accepted October 22, 2018 